\title{
IMPUESTO A LA CARNE: LA IRRUPCIÓN DE UNA ESCRITURA ANTIEDÍPICA Y ANÁRQUICA, DESDE LA ABYECCIÓN DEL CUERPO FEMENINO
}

\author{
Teresa Fallas Arias
}

\begin{abstract}
RESUMEN
En este acercamiento a la novela Impuesto a la carne (2010) de la escritora chilena Diamela Eltit analizo, desde la perspectiva de género, la irrupción de una escritura antiedípica y anárquica que experimentan una madre y su hija desde la abyección de sus propios cuerpos. Sitiadas e impotentes frente al sistema que las enajena y tortura, ensayan una escritura que irrumpe en los silencios, en las entrelíneas, en las frases inconclusas y en las reiteraciones lingüísticas; una grafía con la cual rechazan al patriarca y sus leyes, cuentan lo silenciado por la historia oficial y se rebelan ante los roles socioculturales.

Palabras clave: escritura antiedípica, abyección, anarquismo, patriarcado, neoliberalismo.
\end{abstract}

\begin{abstract}
In this approach to the novel Impuesto a la carne (2010) from the Chilean writer Diamela Eltit I analyze, from a gender perspective, the irruption of an anti-Oedipal and anarchic writing experimented by a mother and her daughter from the abjection of their own bodies. Besieged and powerless, facing a system that alienates and tortures them, they rehearse a narrative that bursts in the silence, in between the lines, in the incomplete phrases and the linguistic reiterations, a writing with which they reject the Patriarch and its laws, they tell the silenced as the official account and rebel against sociocultural roles.
\end{abstract}

Key words: anti- Oedipal writing, abjection, anarchism, patriarchy, neoliberalism.

\section{Introducción}

\begin{abstract}
Quizás sólo las constelaciones simbólicas del arte y de la literatura, de la reflexión estética y del pensamiento crítico, sepan deslizar el trabajo de recordar por los huecos de la representación, por las fallas del discurso social y sus lapsus, por todo lo que entrecorta la sintaxis ordenadora de las recapitulaciones demasiado finitas con el irregular fuera-de-plano de sus motivos truncos y sus visiones trizadas. Le corresponde al arte y la literatura, al pensamiento crítico y la crítica cultural, recoger estas marcas de lo incompleto para que lo fisurado y lo residual del pasado cobre el espesor valorativo que les niegan los saberes totalizadores de la unidad, la síntesis y la recapitulación.
\end{abstract}

(Richard 2010: 181-182)

Dra. Teresa Fallas Arias. Profesora de Comunicación y Lenguaje de la Escuela de Estudios Generales de la Universidad de Costa Rica.

Correo electrónico: tefallas@gmail.com

Recepción: 14- 11- 2012

Aceptación: 08- 01- 2013 
Entre terremotos-tsunamis, reivindicaciones mapuches y el ascenso de un gobierno de derechas, después de 20 años de regímenes de centroizquierda, se festejó en setiembre de 2010 el Bicentenario del republicanismo en Chile. Para celebrarlo se crearon premios, medallas, concursos, emisiones de estampillas, foros, himnos, conciertos, se modernizó el estadio nacional -campo de concentración de prisioneros políticos durante el golpe pinochetista- y se inauguró el Museo de la Memoria y los Derechos Humanos. Con estas actividades el gobierno de Sebastián Piñera pretendió emular o anular las comisiones de la verdad, los parques, los monumentos, los museos, los montajes fotográficos, las instalaciones, los filmes y las narrativas, con las cuales se ha intentado, durante las últimas décadas, censurar las amnesias histórico-políticas, impugnar las amnistías otorgadas a los tiranos y recuperar la memoria del genocidio ejecutado por el terrorismo de Estado en Chile; unas políticas y estéticas que se mantienen vigentes por su carácter eminentemente político y su potencial simbólico y transformador, pese al boicot institucional.

Inscrita en las narrativas contra-hegemónicas, con las cuales se intentó desmontar la celebración del bicentenario en Chile, se publicó Impuesto a la carne, novela donde la escritora Diamela Eltit reflexiona, a través de las voces marginales de dos viejas bicentenarias y anarquistas, sobre los doscientos años de ciudadanía en el republicanismo. Si en Lumpérica fue la plaza el espacio en el cual Eltit experimentó con todo tipo de escrituras móviles para revelar la crisis de la sociedad, secuela de la tiranía de Augusto Pinochet, en Impuesto a la carne desarrolla la trama de la decadencia neoliberal en un hospital-territorio-país-patrianación donde el cuerpo femenino se convierte en mercancía y los médicos encarnan a los generales-militares, según el juego de palabras recreado por la autora.

En este acercamiento a la última novela de la escritora chilena publicada en 2010, año en el que se festejó el bicentenario, me dejo seducir por el núcleo familiar conformado por una madre-hija, cuerpo sitiado por los médicos-generales para experimentar y negociar con sus órganos. Esta peculiar familia chilena, inmovilizada en el nosocomio y en el tiempo, logra desafiar la ley del padre al desconocer la figura paterna y a su imagen sustituta representada por el pater patriae o cuerpo del déspota. El rechazo del patriarca y sus leyes posibilita la irrupción de una práctica de escritura antiedípica y anárquica desde la abyección de sus propios cuerpos; una escritura acusatoria de las experiencias límites que les inflige el sistema de salud público chileno desmantelado por las políticas neoliberales y una grafía de resistencia pues madre-hija se rebelan ante los roles estipulados socio-culturalmente, sospecha que intento dilucidar en esta lectura.

\section{De teorías sobre patriarcas-militaristas}

Respecto a la figura del déspota, como sustituto simbólico del padre biológico, ha reflexionado Kemy Oyarzún en "Desnaturalizar las diferencias: sexo, cultura, poder". En este manuscrito la estudiosa afirma que en Chile siempre se habló de los próceres como padres de la patria, pero es con la dictadura, posterior a 1973, cuando el déspota religó el cuerpo nacional al suyo, pues Pinochet creyó encarnar el cuerpo patrio al proclamarse "ante todo, el Tata, padre de la familia, de un Estado que se quiere representar como familia, como clan" (Oyarzún 2000: 274). Con una práctica totalitaria del poder el dictador trascendió como pater patriae y como tal se apropió, real y simbólicamente, de las mujeres al adjudicarse el derecho de heterodesignarlas, "de producir discurso acerca de ellas, de lo que son y, sobre todo, de lo que deben ser” (Amorós 2008: 193).

Este tipo de poder se prolongó, como una especie de pacto sanguíneo-patriarcal, durante la post-dictadura tiempo en el cual los Gobiernos de Concertación consideraron 
perversa toda desfamiliarización, penalizada con los mismos mecanismos usados por la antigua maquinaria despótica (Oyarzún, 2000: 274). El conservadurismo político, moral y epistemológico de tales gobiernos se percibió, fundamentalmente, en el énfasis dado a la familia como representación ideológica del Estado, pese a que durante este período el EstadoNación estaba en crisis debido a la adopción del neoliberalismo, sistema económico al que se adscribió Pinochet tras el golpe de estado.

Con la glorificación de la familia durante la dictadura y los Gobiernos de Concertación, se impuso un modelo semejante al manipulado por el "discurso burgués de principio del siglo XIX" (Delsing 1997: 124), el cual se articuló desde dos bloques de poder: el político que representó los intereses económicos e ideológicos y el de la Iglesia Católica que se aferró firmemente a sus doctrinas. Desde esta perspectiva, la mujer es juzgada como promotora del desarrollo nacional obligándosele a suministrar hijos productores y gestores a los diferentes regímenes. En ese sentido se prohibió el control de la natalidad y la sexualidad femenina fue considerada "productora de armas de trabajo, por un lado, y de personal disponible para llevar a cabo su ideología (Brito 1997: 67), pues por el cuerpo de la mujer chilena pasó no solo "la producción de bienes nacionales y su expansión territorial. Por el vientre de la mujer, se construye la historia y se hace posible retramar zonas dejadas de lado" (Brito 1997: 67).

Bajo la óptica gubernamental la mujer debía consagrarse durante "este período histórico a la tarea de construir "un Chile grande" (Brito 1997: 67). Con ese fin los regímenes diseñaron una política referente a la maternidad donde la madre pasó a ser "la columna vertebral que educa y transmite los valores que sustenta el Supremo Gobierno" (Brito 1997: 67) y "su vientre, su capacidad fértil, encuentra un nuevo sesgo: es un bastión militar" (Brito 1997: 71). Así la mujer-madre se constituyó en la reserva moral de la patria, pues, según afirma Nelly Richard:

\footnotetext{
El deslizamiento de lo maternal-familiar hacia lo patrio será efecto de una retórica patriarcal-militarista que erige a la Nación en aquel bien supremo que el sacrificio de las madres deberá defender contra el peligro anarquizante de la revolución, para salvar así lo "familiar" (tradiciones y convenciones) de las rupturas de signos con que las fuerzas del cambio pervierten la tranquilidad del orden social (Richard 2010: 59)
}

En la relación familia-sociedad se instituyó que la mujer debía obedecer los lineamientos despótico-patriarcales o de lo contrario se le marginaba hasta ser "expulsada del paraíso patrio que se pretende fundar. De adherir, lo debe hacer sumisamente; de no hacerlo, ella, como madre, desestabiliza la familia chilena católica" (Brito 1997: 71). De esa manera se le exigió acatar las políticas concernientes a la contracepción y al aborto y someterse a las normas dictadas por el Ministerio de la Familia las cuales estipulaban que la familia era "el núcleo básico de la sociedad" (Brito 1997: 70) y las familias debían estar "conformadas por los hombres, las mujeres y los hijos de este país" (Brito 1997: 70).

El énfasis sobre la institución familiar, vinculada a las identidades y construcciones simbólicas genéricas por cuanto "las identidades de género se forjan [...] en el seno de las constelaciones familiares" (Oyarzún 2000: 275), condujo a que durante la dictadura y el período de concertación se produjeran divergencias respecto al empleo de la palabra género, especialmente durante los preparativos para asistir a la IV Conferencia Mundial sobre la Mujer en Beijing, en 1995. Los desacuerdos "se dieron en torno a la categoría de género y a la aceptación de las mujeres como sujetos de derechos reproductivos" (Olea 2000: 57), pues conceptualizar significa politizar para los grupos oprimidos y lo que menos querían los Gobiernos de Concertación era politizar un concepto que sacara a relucir la explotación y la subordinación sociocultural de las mujeres. Según la lógica de dominación masculina no había nada que discutir por cuanto las mujeres 
pertenecemos "como género-sexo al genérico masculino en su conjunto" (Amorós 2008: 54), pero al desestimar los debates, exhibiendo el más rancio conservadurismo, "Chile se convirtió en el único país que condenara por masiva votación parlamentaria, el libre uso de la palabra "género" en un documento oficial" (Oyarzún 2000: 276).

En este contexto donde el discurso fascista se apoyó en la ideología familiaristacatólica-moralista, para activar "la subordinación femenina al paradigma del Estado y la Nación con sus estereotipos de obediencia de la mujer-madre y de la mujer-esposa al Pater, al jefe de familia y al jefe de la Patria" (Richard, 2010: 59), se produjo la búsqueda de nuevos lenguajes en las prácticas de escrituras femeninas

[...] para decir el autoritarismo de forma que exhibiera una institucionalidad históricamente excluyente de las mujeres. En esa resistencia se configuró la voluntad de una escritura de mujeres antiedípica, ilegítima, sin reconocimiento de padre ni madre, oscilante en múltiples (des)identidades, buscando asumirse en lo oscuro de un signo interrogante de las verdades y las genealogías dominantes. (Olea 2000: 58)

Una escritura similar a la desplegada por Eltit en Impuesto a la carne, novela donde madre-hija matan al padre cuando desconocen al padre biológico y rechazan la pertenencia al clan del pater patriae chileno, déspota experto en acosos, torturas y asesinatos, disyuntivas entre las que se desplazan estas viejas anarquistas quienes, a través del drama experimentado en sus propios cuerpos, se niegan a rendirle honores al poder a lo largo de doscientos años de vida republicana.

La identificación fallida con el padre, la impugnación de la ley paterna encargada de prohibir, separar e impedir el contacto con la madre y el rechazo de la política materna-familiardictatorial las lleva a unirse, según confiesa la hija, "de una forma que podría considerarse maníaca o excesivamente primitiva. Lo hice porque desde nuestro nacimiento [...] estuvo claro que éramos dos seres o dos almas solas en el mundo" (Eltit 2010: 18). Rotos los lazos con el padre y sin parientes ni amigas, desaparecidas como desaparecieron miles de chilenos durante la dictadura de Pinochet, la alianza madre-hija se fortalece al repudiarlas el régimen por sus tentativas de reivindicación anarquista, tildándolas despectiva y reiteradamente curiches, monstruosas, sordas, frígidas, castradas, decrépitas, bajas, feas, seriadas y perras hemorrágicas. El vínculo materno-filial se consolida "a través de la fuerza de la exclusión y la abyección" (Butler 2005: 20), pues son personificadas como lo abyecto: aquello que "perturba una identidad, un sistema, un orden [...] que no respeta los límites, los lugares, las reglas" (Kristeva 1988: 9).

Del enfoque peyorativo deriva el confinamiento de las viejas en el hospital-paíspatria-territorio-nación donde experimentan la sordidez del sistema de salud a través del equipo médico-militar, torturador del cuerpo femenino. Incomunicadas por fraguar la revuelta de la palabra-escritura testimonian su exclusión, por rebelarse al sistema neoliberal-patriarcal y a las representaciones estipuladas a las mujeres. Constatan, además, que son "vigiladas atrozmente por una serie de médicos [...] como si fuéramos una infección incandescente o un titilante y fraudulento desecho" (Eltit 2010: 20), pero el asedio no les impide inaugurar una práctica de escritura que irrumpe desde sus cuerpos mutilados en un intento por conquistar una identidad, una historia y una memoria.

\section{Cuerpo a cuerpo con la escritura}

Entraré en mi cuerpo como en un libro para transformarlo en memoria. Quiero preparar mi cuerpo para convertirlo en una crónica urgente y desesperada. Dejaré abiertas zonas para la interpretación y no vacilaré en denunciar mis debilidades y hasta mis abyecciones. (Eltit 2010: 129). 
Empecinada en descubrir los hechos silenciados por los diferentes regímenes, Diamela Eltit se remonta dos siglos atrás para revelar el lado oscuro de la historia chilena mediante las evocaciones, los murmullos y las voces de dos viejas anarquistas quienes, entre incertidumbres, amnesias y reiteraciones, actúan en Impuesto a la carne como una especie de conciencia social memorialista de la cual emergen los pasajes nacionales más cruentos desde la adopción del republicanismo en Chile. Con los recuerdos emergen episodios tergiversados por los gobernantes y olvidados por la sociedad, en cuenta aquel donde hubo "cientos de muertos en una rebelión popular. Eso fue hace un siglo, murmura mi mamá, un siglo ya, el siglo de los levantamientos, ese siglo en que se modeló la figura anarquista de mi madre, mi mamá que me abrió los ojos, que me abrió los ojos, que me abrió los ojos." (Eltit 2010: 123)

Este levantamiento popular contra el impuesto a la importación de carne argentina y parafraseado por Eltit en el título de la novela, fue respaldado por el anarquismo, especialmente por las mujeres defensoras de esa ideología en quienes renace la conciencia anarquista, notoria en la expresión "me abrió los ojos" que, repetida tres veces, le permite a la hija apropiarse de la herencia anárquico-materna, legado defendido desde entonces como forma de vida y escritura. Sin importarles que en tiempos de libre mercado el anarquismo sea una ideología inoperante, madre-hija se comprometen con este movimiento y sus luchas, aunque para sobrevivir debieron transformarse, en ciertos momentos, en "un simulacro de obediencia y hasta de sumisión" (Eltit, 2010: 146) o ser registradas como "migrantes, sí, migrantes como quieren declararnos a nosotras, a ti y a mí, para luego dar origen a una deportación" (Eltit 2010: 141).

Confinadas en el hospital-país-patria-nación traman un tipo de escritura que emana desde la abyección de sus propios cuerpos; una grafía de la revuelta que refulge o se desvanece, conforme se articula, para contar lo no dicho por la historia oficial. Sitiadas por los médicosgenerales e impotentes frente al sistema que las enajena y las tortura, madre-hija ensayan una escritura que irrumpe en los silencios, en las entrelíneas, en las frases inconclusas, en las reiteraciones lingüísticas y en el "lenguaje de la falta, del miedo que lo aborda y lo bordea. Aquel que trata de decir ese "no todavía lugar", ese "no-lugar" (Kristeva 1988: 55).

Con una escritura huidiza y fragmentada se refieren a los hechos confiscados por los distintos regímenes impregnando de pasión libertaria sus "argumentos con el fin de que se entienda cómo se ha organizado la trastienda de la historia" (Eltit 2010: 31) y demandan se les "permita hacer un milímetro de historia" (Eltit 2010: 31). Empeñadas en revelar sucesos no relatados se dicen y desdicen pues, consciente o inconscientemente, reconocen que la censura previa no va a permitir que circule "ni un pedacito de palabra. La nación o la patria o el país van a aplastar la revuelta de la sílaba. No. Ni en cuatrocientos años más" (Eltit 2010: 31). Pero tal desautorización no les impide conferirse la potestad para

\footnotetext{
dar cuenta de la historia y detenernos en cada uno de los episodios turbios o en aquellos que portan una metafísica falsificada. Porque nos proponemos enfrentar un tiempo colmado de datos inciertos o definitivamente silenciados. Queremos resumir, repensar, repeler ciertas versiones impropias. Somos testigos de una cantidad tan significativa de años que podríamos oficiar como las más confiables historiadoras inorgánicas de nuestro extenso tiempo. (Eltit 2010: 33)
}

Frente a una historia fraudulenta que se abstiene de enjuiciar las iniquidades de los déspotas, estas viejas anarquistas se vislumbran en el papel de escribas y se facultan para delatar los hechos encubiertos por la oficialidad. La autodenominación paródico-sarcástica de historiadoras inorgánicas no remite al intelectual orgánico, término acuñado y desarrollado por Antonio Gramsci, sino al cuerpo del cual emerge la escritura; un cuerpo mutilado por 
los médicos-generales quienes comercian los órganos a altos precios, incentivo que los lleva a ensañarse con los genitales aunque por los ovarios ofrecen una miseria (Eltit 2010: 101).

Estas viejas se valen de la escritura para condenar el saqueo abusivo y persistente de sus órganos, ejecutado por el sistema de salud chileno que, desmantelado por las políticas privatizadoras neoliberales introducidas por Pinochet, juzga el cuerpo femenino como una mercancía en el juego de la oferta y la demanda. Por ello están obligadas "a vender todo, aún lo que está fuera de nuestra imaginación" (Eltit 2010: 138), "vender algo, no sé qué. Vender una parte de nosotras" (Eltit 2010: 139). "Podría, dice mi mamá, vender uno o dos o tres dedos [...] pero todavía no hay un espacio, un verdadero espacio para los dedos" (Eltit 2010: 138).

La percepción de sus cuerpos como objetos-mercancías las lleva a adquirir conciencia de género, perspectiva desde la cual denuncian que la historia de las mujeres carece enteramente de historia y que llevan mucho tiempo "esperando un turno, cualquiera, esperando una hora, cualquiera, y esperando ser invitadas a un festejo, cualquiera, esperando, esperando, esperando." (Eltit 2010: 149). Además de constatar la postergación de sus necesidades y deseos confirman que las mujeres habitan "en los escalafones más insignificantes del tendedero social" (Eltit 2010: 130), evidente en el desprecio del médico-general quien enfurecido con la madre "se abocó a la estructura de sus genitales [...] Y luego se abalanzó artero para ensañarse con ella de un modo tan salvaje que en vez de examinarla la desgarró hasta que le causó un daño irreparable" (Eltit 2010: 13).

Estas prácticas perversas asemejan a médicos y militares, pues tanto el sistema de salud como el político tienen "el poder o la gracia de permitir la vida y decidir la muerte" (Eltit 2010: 25). La analogía entre estas entidades va más allá cuando madre-hija relacionan a la Junta Militar con la Junta Médica, conexión de la cual deriva el juego de palabras ingeniado por Eltit y reiterado por la hija:

\section{Mi mamá afirma que los médicos generales eran atentos y olvida senilmente que sus características opresoras sobre nosotras los volvían temibles, violentos. Se niega a aceptar mi madre que ellos no tenían escrúpulos porque prácticamente no nos examinaban y nos trataban con una violencia que no comprendo cómo ha podido disculpar. Así son los generales. (Eltit 2010: 54)}

$\mathrm{Si}$ en algunos segmentos reconocen que su escritura es una crónica marginal y prescindible, la evidencia no las detiene conscientes de que sus propios cuerpos "portan los signos más confiables para establecer el primer archivo del desastre. El más célebre y el más confiable" (Eltit 2010: 127). Tal certidumbre las legitima para testimoniar la depredación de sus órganos y la de sus compañeras de infortunio cuando rememoran, en su papel de escribas, "las muertes masivas de las mujeres. De no sé cuántas mujeres" (Eltit 2010: 156); un suceso a partir del cual se consideran en

\footnotetext{
la obligación histórica de redactar las memorias de la angustia y del desvalor. Unas memorias que serán escritas a lo largo de los próximos doscientos años con el esmero de los antiguos calígrafos que dejaron su sangre en la letra. Vamos a escribir pausadamente los hechos que conocemos para dejar por escrito su importancia y su existencia. (Eltit 2010: 156)
}

De esta manera reivindican los agravios y las muertes de las mujeres en los hospitales, por la desidia de los encargados de la salud pública. Además critican que el equipo sanitario las someta a todo tipo de mutilaciones y que, entre otros ultrajes, no les cambien las sábanas: "Y para qué las van a cambiar, dice mi mamá, si ya ligerito se van a morir, para qué, dime tú, les van a poner sábanas limpias y además qué te importan las sábanas, eso es irrisorio" (Eltit 2010: 162). Aunque parece absurdo ocuparse del cambio de sábanas, entre tanto dolor y miseria, son estos implementos los que 
remiten a una serie de imágenes hemorrágicas con las cuales aluden a la "vertiginosa escenificación [...] de una auto-parición siempre fracasada y que debe empezar de nuevo infinitamente, dado que la esperanza de renacer está soslayada por el clivaje mismo" (Kristeva 1988: 75). Esto por cuanto Madre-hija no logran separarse al matar al padre, quedando atrapadas en un solo cuerpo.

La impresión de que madre-hija son una sola persona se prolonga a lo largo de la novela, pues tal parece que una de ellas inventó a la otra para hacernos creer que tiene una aliada. Esta percepción aumenta al descubrir que la hija es, quien narra las citas- revelaciones maternas y se profundiza al observar la enigmática foto en la portada de la novela, imagen siniestra de la cual parece no haber escapatoria porque los límites entre ellas se pierden y se confunden sin que consigan independizarse una de la otra. Así lo reconoce la hija cuando exclama: "mi madre se queja dentro de mí, gruñe, y gruñe y me dice no, no, no lo digas, no lo sigas diciendo, no. Se mueve agitada en mi profundidad torácica. Está asustada mi mamá y me implora. Busca mi silencio. Mi madre anarquista teme que se nos avecine una represalia" (Eltit 2010: 182).

El sobresalto entre ellas es habitual pues además de practicar una escritura de resistencia promueven las mutuales, instituciones en las cuales confían encontrar la solución al descalabro del sistema de salud público. Es conocido que desde su origen el anarquismo fundó estas entidades para defender a las poblaciones de la indiferencia estatal y de los abusos del poder. De estos ideales germinan las intenciones de madre-hija de inaugurar una mutual de la espina dorsal para ponerse de pie y no doblegarse, sin importarles la incompetencia de este movimiento en un "presente insensible a todo lo que no es, pragmáticamente, utilidad y ganancias" (Richard 2010: 14), conscientes de que la "medicina sufre una de las peores crisis de su historia. Los archivos que la consignan son guardados en bóvedas severamente selladas" (Eltit 2010: 162).

A pesar del acoso y el saqueo de sus órganos madre-hija inician la búsqueda de su propia comuna, para lo cual planean viajar al norte donde aseguran encontrarán "un techo desde donde podamos vigilar y cuidar nuestra renovadora sociedad de resistencia" (Eltit 2010: 167), pero debido a las intrusiones de los médicos-generales se anticipan implementándola, precipitadamente, en "la patria de mi cuerpo o en la nación de mi cuerpo o en el territorio de mi cuerpo, mi madre por fin estableció su comuna. Se instaló una comuna en mí rodeada de órganos que se levantan para protestar por el estado de su historia" (Eltit 2010: 185).

Atrapadas en una relación telarañosa el vínculo parental resulta fastidioso, como se confirma en los continuos amagos de aborto o en la sordera simulada de la hija ante las constantes injurias y agresiones maternas, pero el nexo se mantiene y se refuerza pues, según reconoce la hija, la "unión, la mía y la de mi madre, es una alianza indisoluble que nos ha mantenido vivas" (Eltit 2010: 79) y les confiere la energía suficiente para sublevarse ante "una nación o un país o una patria médica plagada de controles parciales o totales" (Eltit 2010: 30).

Además están conscientes de ser las únicas suscriptoras de la gesta anárquica-libertaria pues el poder dictatorial aniquiló el vínculo comunitario y la solidaridad entre los chilenos al recurrir a tres medios de control: la represión, el mercado y la televisión, como lo expusiera Joaquín Brunner en Un espejo trizado; ensayos sobre cultura y políticas culturales (1988) y reafirmara Nelly Richard en Crítica de la memoria (1990-2010):

No habría cómo explicar el disciplinamiento de las subjetividades sociales que se plegaron tan fácilmente al diseño conformista de la transición chilena, sin esta alianza entre mercado y televisión que reorganizó la esfera simbólico-cultural de las pulsiones y los deseos (ya no de cambio y transformación sino de acostumbramiento y relajo) a través de las industrias del consumo y la entretención que se aplicaron en distraer las mentes, capturadas por guiones comerciales, de la visión de lo siniestro heredada de la dictadura. (2010: 35) 
Sin partidarios, las viejas anarquistas observan impotentes a los fans que pululan en la sociedad y acuden a festejar los actos cívicos cuando "el país o la patria ya totalmente bicentenaria renueva de manera frívola sus votos con una ceremonia laboriosa e impregnada de un encendido matiz oficialista" (Eltit 2010: 143). Estos personajes que inundan la trama novelística respaldan al régimen que se fortalece y se propaga con la "implementación salvaje de una economía de mercado" (Richard 2010: 35). Además los fans proclaman su lealtad al sistema, incapaces de percibir la manipulación y el control ejercido por éste mediante ofertas y adelantos digitales en el "profuso mercado de obsesiones tecnológicas que manejan [...] ese universo que los impregna de energía y los consume" (Eltit 2010: 109).

Distanciadas de los fans, y cautelosas ante los insultos que estos les pueden endosar en los blogs, donde "millones de millones, de millones de fans se conectan, se conectan, se conectan, se conectan a sí mismos, a sí mismos" (Eltit 2010: 109), los inculpan por su desmemoria del pasado ignominioso, por dejarse atrapar en las distracciones consumistas y por entregarse con fervor a sus funciones burocráticas al cumplir "fielmente sus labores de meras infraestructuras o de escoltas o de vigías o de entretenciones para el plantel" (Eltit 2010: 16). Señalados insistentemente a lo largo de la novela, los fans les permite contrastar sus actuaciones pues mientras ellas enarbolan la escritura como bandera de resistencia, los fans se afilian al poder, sin culpas ni vergüenzas, seducidos por modelos de gratificación consumista cuyas imágenes los in-cita a

\footnotetext{
[...] olvidar el drama de cualquier peso de conciencia ligado al abismo de la desaparición y al suplicio de los cuerpos torturados durante la dictadura militar. La fantasía de los productos de consumo globalizado se encargó de propagar la excitación de lo diverso y lo cambiante para fabricar olvido y desmemoria [...] el mercado se valió del gusto por la novedad con la que se propaga la exaltación neoliberal de lo transitorio, para que los excesos dramáticos de la historia y la memoria, como remanentes de un ayer desgastado, fueran parte de lo que el barrido consumista debía dejar irremediablemente atrás sin pena ni gloria, sin remordimiento. (Richard 2010: 36)
}

Tampoco se vinculan con las barras futboleras las cuales, anestesiadas por el efecto de manada de los estadios, solamente "aúllan su necesaria cuota de ira y de dolor ante el cambio de las reglas de juego" (Eltit 2010: 122) o "aúllan su rencor ante las sucesivas suspensiones de cada uno de los partidos de la patria" (Eltit 2010: 125). Las critican también por el fanatismo patriotero que las desvinculó de la sociedad pues sus cuerpos dejaron de pertenecerles al comportarse exclusivamente como barras futboleras. Con la escenificación de estas turbas desenmascaran "lo que la versión oficial de la práctica del fútbol oculta: que no todo en el juego es pasión y entretenimiento, sino también control y enriquecimiento" (Villena 2006: 14), recursos con los cuales lucran gobernantes y empresarios quienes manipulan el juego en función de sus propios intereses.

Inmersas en un sistema de libre competencia, contrario a sus vocaciones anarquistas, reinventan un lenguaje que deben camuflar en su escritura, pues éxito, venta y ganancia son las palabras que predominan en la sociedad, mientras hay "términos inadecuados o peligrosos o torcidamente silentes (Eltit 2010: 161). De ahí la astucia de madre-hija al repudiar, aparentemente, "todos y cada uno de los términos que ahora no se pueden nombrar. Tenemos que dejar de pronunciar las palabras que parezcan peligrosas, anacrónicas o anarquistas [...] No menciones nunca más la palabra hambre. Olvídala, por favor, dice mi madre" (Eltit 2010: 161). No obstante la palabra vetada aparece aquí y allá, seguida de amonestaciones maternas: "cómo se te ocurre mencionar esa palabra contaminada, totalmente prohibida por los severos controles electrónicos de la historia, ¿te volviste loca?, ¿cómo te atreves? (Eltit 2010: 160). 
Impugnadoras de los entes jerárquicos y fuertes defensoras de la ideología anarquista se sublevan ante la sociedad cuando deciden no desempeñar ningún rol estipulado para las mujeres. Se niegan a realizar labores domésticas y a tener hijos y parejas subvirtiendo la ideología fascista-familiarista-católica inaugurada por la dictadura pinochetista. Si trascienden prejuicios religiosos en las obsesiones de la madre al juzgar una pesada cruz a su hija, esta se subleva de inmediato y le prohíbe tales desatinos:

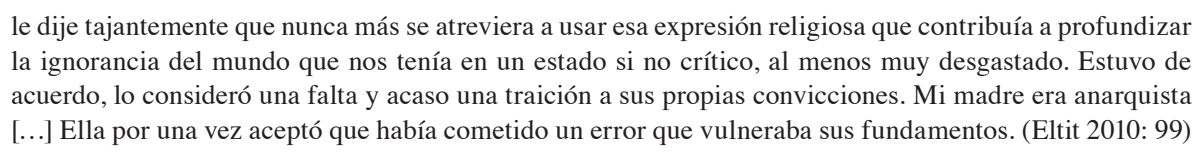

Deslegitimadas, marginadas y acusadas de advenedizas por ejercer libremente la ideología anarquista, Madre-hija piensan en el destierro como la única salida a su situación, sin embargo sus planes de emigrar no prosperan porque en el último momento surge una especie de patriotismo que las detiene; así se intuye en las revelaciones de la hija:

\footnotetext{
Debemos irnos, abandonar la patria o el país o este hospital, tenemos que vender algo, no sé qué. Vender una parte de nosotras. Pero mi madre no dejará jamás el hospital, la patria [...] Miro a mi mamá de reojo, ¿qué veo?, su perfil ondulando como una bandera enteramente nacional, patriótica. (Eltit 2010: 139)
}

Además los intentos de fuga se malogran pues madre-hija están conscientes de que no abandonarán el hospital-país-patria-nación por sus propios medios, que morirán por el saqueo de sus órganos. Pero la amenaza de muerte no impide su denuncia, en un período donde impera el libre mercado y Chile se erige como el emporio de la producción y de las exportaciones en América Latina, pues es presumible que sus cuerpos, junto con los cuerpos de los desaparecidos y asesinados por el terrorismo de estado, sean deportados como parte del cobre-mineral-rojizo-sangre que el gobierno chileno comerciará cuando ponga en marcha "un operativo para decretar la demolición y la expatriación de nuestros cuerpos. Minas. Minerales. Nuestros huesos cupríferos serán molidos en la infernal máquina chancadora. El polvo cobre del último estadio de nuestros huesos terminará fertilizando el subsuelo de un remoto cementerio chino" (Eltit 2010: 187).

\section{En el umbral}

No pretendemos, mi madre y yo, convertirnos en voceras del tiempo ni menos adjudicarnos la totalidad de la historia. Sólo intentamos, de manera pausada o solapada, escribir la crónica más ardiente de la postergación

(Eltit 2010: 172)

La crónica más ardiente de la postergación, mientras están confinadas en un hospitalpaís-territorio-nación, es la escrita por madre-hija viejas anarquistas a las cuales Diamela Eltit les confiere el papel de escribas en Impuesto a la carne. En esta novela la escritora chilena transgrede la retórica gubernamental celebratoria del bicentenario, a través de los murmullos y las voces de estas marginales quienes, convertidas en la conciencia social chilena, intentan recuperar la historia silenciada a lo largo de la vida republicana, especialmente la ocultada por la dictadura pinochetista patrocinadora del neoliberalismo y por los Gobiernos de Concertación que respaldaron las políticas neoliberales, desmanteladoras del estado de bienestar en Chile.

Si la praxis anarquista consistió en repudiar al Estado burgués y al mercantilismo, es predecible que las invectivas de madre-hija se dirijan contra los culpables de los pasajes más 
sórdidos de la historia chilena y los responsables de la apertura de libre mercado en Chile. Siendo el anarquismo una ideología promotora de la emancipación humana y combativa de todo tipo de jerarquías, se justifican los ataques a través de la revuelta de la palabra-escritura contra el poder despótico-sanguinario y contra el discurso fascista-familiarista-católico paradigma estatal dictaminador de la sumisión de la mujer-madre-esposa.

Al matar al padre biológico y al pater patriae madre-hija subvierten el arquetipo de familia glorificado por el Estado negándose a suministrar hijos productores y gestores del sistema y a construir el país reclamado por los déspotas. Infringen, de igual manera, las representaciones tradicionales cuando se niegan a cumplir labores domésticas, ocupadas en gestar mutuales para rescatar el sistema de salud chileno arruinado por la implementación de políticas privatizadoras, y en defenderse del trasiego que hacen los médicos-generales con sus órganos en el hospital-territorio-patrio. Sus nombres quedan en el anonimato en un intento quizás por fusionarse con las mujeres muertas en los hospitales y con los desaparecidos durante el régimen pinochetista.

Con su escritura de resistencia Madre-hija se rebelan a ser partidarias del sistema como los fans y las barras futboleras, especie de remedos humanos desmemoriados que aparecen una y otra vez a lo largo de la novela; entes manipulados y controlados por gobernantes y empresarios mediante artimañas de exaltación neoliberal; unas masas desmovilizadas y despolitizadas que, fanáticas del consumismo y del entretenimiento, no se percatan del desmantelamiento de los servicios públicos en su país.

Extranjeras o exiliadas en su propia tierra estas viejas anarquistas, cuyos cuerpos se convierten en mercancía, se rebelan ante las prácticas intervencionistas y disciplinadoras del sistema aunque terminan siendo trasterradas con el cobre, mineral rojo-sangre del que se han beneficiado pocos chilenos, mientras la población sigue esperando que el crecimiento económico se proyecte a toda la sociedad.

\section{Bibliografía}

Amado, Nora y Nora Domínguez. 2004. Lazos de familia: herencias, cuerpos, ficciones. Buenos Aires: Paidós.

Amorós, Celia. 2008. Mujeres e imaginarios de la globalización: reflexiones para una agenda teórica global del feminismo. Rosario: Homo sapiens.

Bordieu, Pierre. 2000. La dominación masculina. Barcelona: Editorial Anagrama.

Brito, Eugenia. 1997. "Roles sexuales: diversas escenas”. En: Grau et al., 65-91.

Butler, Judith. 2005. Cuerpos que importan: sobre los límites materiales y discursivos del "sexo". Buenos Aires: Paidós.

Delsing, Riet. 1997. "La familia: el poder del discurso". En: Grau et al. Discurso. Género y poder. Discursos públicos: Chile 1978-1993. Santiago: LOM Ediciones.

Eltit, Diamela. 2010. Impuesto a la carne. Santiago: Editorial Planeta.

2000. "Cuerpo y fulgor". En: Olea. Escrituras de la diferencia sexual. Santiago: LOM Ediciones.

Grau, Olga et al. 1997a. Discurso, género y poder. Discursos públicos: Chile 1978-1993. Santiago: LOM Ediciones. 
1997b. "Familia: un grito de fin de siglo". En: Grau et al., 127-148.

Kristeva, Julia. 1988. Poderes de la perversión. México: Siglo XXI.

Masiello, Francine. 2000. “Cuerpos y citas”. En: Olea (Ed.), 183-193.

Navarro, Ginés. 2002. El cuerpo y la mirada. Barcelona: Anthropos.

Olea, Raquel (Ed.). 2000a. Escrituras de la diferencia sexual. Santiago: LOM Ediciones. 2000b. "Femenino y feminismo en transición". En: Olea (Ed.), 53-60.

Olivier, Christiane. 1997. Los hijos de Yocasta. México: Fondo de Cultura Económica.

Richard, Nelly. 2010. Crítica de la memoria (1990-2010). Santiago: Ediciones Universidad Diego Portales.

Villena, Sergio. 2006. Golbalización Siete ensayos heréticos sobre fútbol, identidad y cultura, San José: Grupo Editorial Norma.

Zorrilla, Sergio. 2000. "Del cuerpo al goce y a la sexualidad como forma de subjetividad; la necesidad de reivindicar nuevamente la corporalidad". En: Olea (Ed.), 133-148. 
